\title{
Epidemiological Aspects of the First Outbreak of Baylisascaris procyonis Larva Migrans in Rabbits in Japan
}

\author{
Hiroshi SATO $^{1)}$, Haruo KAMIYA ${ }^{1)}$ and Hidefumi FURUOKA ${ }^{2)}$ \\ ${ }^{1)}$ Department of Parasitology, Hirosaki University School of Medicine, Hirosaki 036-8562 and ${ }^{2)}$ Department of Veterinary Pathology, \\ Obihiro University of Agriculture and Veterinary Medicine, Obihiro 080-8555, Japan
}

(Received 17 September 2002/Accepted 20 December 2002)

ABSTRACT. Larva migrans caused by the common raccoon ascarid, Baylisascaris procyonis, is a zoonotic disease of critical importance in North America. Recently we encountered the first proven outbreak of this disease in Japan in domestic rabbits (Oryctolagus cuniculus) in a small wildlife park. In this park, raccoons (Procyon lotor) had been kept for 9 years, and one raccoon was donated to the park by a pet owner 8 weeks prior to the occurrence of an outbreak in rabbits. Of 12 total raccoons, three raccoons including the donated one shed B. procyonis eggs in the feces, and two of these positive raccoons were kept in metal mesh cages on wooden pedestals, $2 \mathrm{~m}$ distant from the rabbit enclosure. Circumstantial evidence indicates that the donated raccoon is the likely source of this outbreak. Treatment of the raccoons with an ascaricide and decontamination by extensive flaming of the cages and the contaminated dirt floor of the park achieved a transient disappearance of ascarids from all 12 enclosed raccoons. Three months after the control measures began, recurrent ascarid infection was detected in three young raccoons of less than 1.5 years of age. The potential risk of serious zoonosis by $B$. procyonis as well as the difficulty in a clearance of contaminated areas should be considered by pet owners and public health workers in Japan.

KEY WORDS: Baylisascaris procyonis, larva migrans, rabbit, raccoon, zoonosis.

J. Vet. Med. Sci. 65(4): 453-457, 2003

The common raccoon ascarid, Baylisascaris procyonis, causes a serious zoonosis resulting in neurological disease. In North America B. procyonis is endemic among raccoons (Procyon lotor), and the larva migrans is common and important for both domestic animals and wildlife [8-11, 14]. The disease has been reported from more than 90 species of mammals and birds there. In human beings, infants are at the greatest risk of heavy infection, and 10 proven $[3,4,6$, $12,18-20]$ and several suspected cases [10] reported in the USA had cerebrospinal larva migrans with poor prognoses. In contrast, adults usually exhibit unilateral ocular involvement or asymptomatic visceral larva migrans, and the infection was reported from the U.S.A. and Germany [2, 5, 13, 15]. Due to these situations, B. procyonis is receiving increased attention in North America and Europe where raccoons are endemic or naturalized.

Recent naturalization of raccoons as well as increase in their population in Japan causes economic and ecological problems [7, 17]. Although the incidence of B. procyonis was documented at $8-40 \%$ in zoo- or broker-kept, or pet raccoons [17], to date the ascarid has never been found in wild raccoons in Japan [1, 17, 25]. However, the situation in Japan is quite fluid as raccoons, probably including ascarid-infected ones, have been widely dispersed as personal pets and may have escaped or been released from captivity.

This report describes epidemiological aspects of the first outbreak of $B$. procyonis larva migrans in rabbits in Japan [21]. Circumstantial evidence indicates that a pet raccoon donated to the park 8 weeks prior to the disease onset in rabbits is likely the source of this outbreak.

\section{MATERIALS AND METHODS}

Animal accommodation in the park and kept raccoons: A syndrome of progressive neurological signs including ataxia and torticollis was noticed in domestic rabbits (Oryctolagus cuniculus) in mid-July of 2000 in a small wildlife park housing dozens of foxes, rabbits, guinea pigs and 12 raccoons [21]. The park is situated in a mountainous area, and animal accommodation included a dirt-floored enclosure for foxes on the top level, 3 dirt-floored enclosures for rabbits (approximately 32, 68, and $131 \mathrm{~m}^{2}$, respectively) surrounded by wire fences on the middle level, and two metal mesh cages and a single wooden hovel with a metal mesh floor for raccoons on the lowest level (Fig. 1). In addition, 3 metal mesh cages for raccoons were placed near the lowest border of the fox enclosure, $2 \mathrm{~m}$ distant from the second rab-

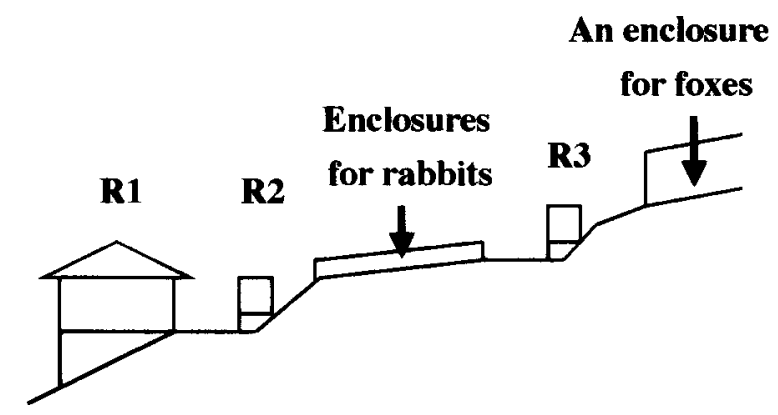

Fig. 1. An outline of animal accommodation arrangements in the wildlife park where an outbreak of $B$. procyonis larva migrans was found in rabbits. Raccoons were kept in a wooden hovel (R1) or metal mesh cages (R2 and R3). 
Table 1. Data on raccoons kept in a wildlife park where larva migrans due to $B$. procyonis was found in rabbits

\begin{tabular}{|c|c|c|}
\hline No. & Age and $\operatorname{sex}^{\mathrm{a})}$ & Origin \\
\hline $1-3$ & 9-year-old, ठे & Purchased from a broker 9 years earlier ${ }^{\text {b) }}$ \\
\hline 4 & 9-year-old, 우 & Purchased from a broker 9 years earlier \\
\hline 5 & 7-year-old, 오 & Purchased from a local pet-shop 7 years earlier \\
\hline 6 & 9-year-old, 우 & Purchased from a broker 9 years earlier \\
\hline 7 & 3-month-old, $\sigma^{7}$ & An offspring of No. 6 \\
\hline 8 & 3-month-old, 우 & An offspring of No. 6 \\
\hline 9 & 15-month-old, ठ ठ & An offspring of No. 6 \\
\hline 10 & $>$ 5-year-old, 우 & Donated from a pet owner 8 weeks earlier \\
\hline 11 & 9-year-old, o & Purchased from a broker 9 years earlier \\
\hline 12 & 15-year-old, o & Purchased from a local pet-shop 9 years earlier \\
\hline
\end{tabular}

a) Age at the time when clinical signs of $B$. procyonis larva migrans were first noticed in rabbits in mid-July.

b) Ten juvenile raccoons, 2 to 3-month-old, were imported from USA, and 4 animals were lost from various reasons before 2000 .

Table 2. Chronological description of the main events related to the outbreak of $B$. procyonis larva migrans in rabbits kept in a wildlife park

\begin{tabular}{|c|c|}
\hline Day & Event \\
\hline-9 & $\begin{array}{l}\text { Water overflow over the rabbit enclosure due to a typhoon, and transfer of all rabbits to the } 2 \text { nd rabbit } \\
\text { enclosure (possible dispersion of embryonated eggs). }\end{array}$ \\
\hline-8 & Division of 43 rabbits collected in a place into 3 rabbit enclosures. \\
\hline 0 & First notice of neurological signs in proportions of rabbits. \\
\hline 15 & Provisional diagnosis of ascarid larva migrans in rabbits. \\
\hline 24 & Fecal examination of kept raccoons; 3 positive for ascarid eggs out of 12 fecal samples. \\
\hline 28 & First administration of an ascaricide to raccoons. \\
\hline 42 & Fecal examination of kept raccoons; all negative for ascarid eggs. \\
\hline 51 & Second administration of an ascaricide to raccoons. \\
\hline 52 & $\begin{array}{l}\text { Fecal examination of kept raccoons; all negative for ascarid eggs. Decontamination by thorough flaming } \\
\text { of most of facility area. }\end{array}$ \\
\hline 55 & $\begin{array}{l}\text { Transfer of young raccoons (Nos. } 7 \text { and } 8 \text { ) to a cage housing previously raccoons infected with B. procy- } \\
\text { onis (Nos. } 9 \text { and 10). }\end{array}$ \\
\hline 78 & Transfer of all raccoons' cages to the lowest place of the facility. \\
\hline 85 & Accidental death of the donated raccoon (No. 10). \\
\hline 91 & Fecal examination of kept raccoons; one positive (No. 9) for ascarid eggs out of 11 fecal samples. \\
\hline 107 & Autopsy of 11 raccoons; 4 (Nos. 6-9) had B. procyonis infection. \\
\hline
\end{tabular}

a) Day after first notice of the outbreak.

bit enclosure. Raccoons kept in the park during the disease onset in rabbits are listed in Table 1: Nos. 1-5 were housed together in one hovel ("R1" in Fig. 1); No. 6 singly and Nos. 7 and 8 together in 2 cages at the lowest level ("R2" in Fig. 1); and Nos. 9 and 10 were housed together, and Nos. 11 and 12 singly in 3 cages on the middle level ("R3" in Fig. 1). Metal mesh cages for raccoons were kept on wooden pedestals. One of 2 caretakers gave food and cleaned the accommodation for raccoons and rabbits every morning.

Major events associated with the outbreak: Neurological signs in the rabbits appeared abruptly and simultaneously in all 3 rabbit enclosures with a higher incidence in the second enclosure. The major events associated with the outbreak of B. procyonis larva migrans in housed rabbits and the control measures employed are chronologically shown in Table 2. After detection of ascarid eggs in feces, the infected raccoons were isolated to limit contact with visitors, and the excreta of all raccoons were treated carefully and decontaminated by flaming with a portable propane torch.

Fecal examination and anthelminthic treatment: Magnesium sulfate-saline flotation and formalin ether sedimentation were performed using $1 \mathrm{~g}$ of feces to detect ascarid eggs. Estimations of egg counts per $\mathrm{g}$ feces (EPG) were made using formalin ether sedimentation. The anthelminthic parbendazole (methyl-5-butyl-2-benzimidazole carbamate) (300 mg, embedded in a piece of sausage) was administered to each raccoon daily for 2-3 consecutive days. Ascarids expelled in feces or parts of parasites recovered from the intestine at autopsy were fixed in hot formalin $\left(80^{\circ} \mathrm{C}\right.$ for $\left.20 \mathrm{~min}\right)$ to kill eggs.

Autopsy of raccoons and parasitological examination: The intestine was removed, longitudinally opened, and thoroughly washed to collect luminal parasites. The rest was minced and digested with an artificial gastric juice contain- 


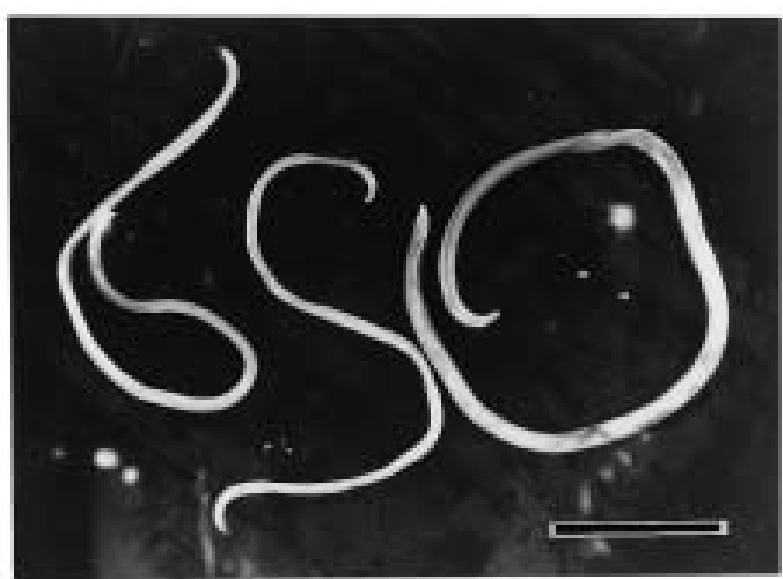

Fig. 2. Expelled B. procyonis adults (M, male; F, female) in the feces of an adult raccoon (No. 10) after anthelminthic treatment. Fixed in formalin. Bar $=20 \mathrm{~mm}$.

ing $0.8 \%$ pepsin and $0.8 \% \mathrm{HCl}$ at $37^{\circ} \mathrm{C}$ overnight to detect juvenile worms in the intestinal wall.

\section{RESULTS AND DISCUSSION}

The first examination of raccoon feces was conducted using samples collected on day 24 after the onset of the disease in rabbits. B. procyonis eggs were detected in 3 of 12 fecal samples; 276 EPG from a raccoon grouped in a hovel (either one of Nos. 1-5), and 150 and 456 EPG from Nos. 9 and 10 raccoons housing together in a cage. After the first administration of the ascaricide, one male and 2 females, 8 males and 9 females, and 2 males and one female B. procyonis (Fig. 2) were recovered from these egg-positive raccoons, respectively.

Before the summer of 2000, caretakers in this park sometimes observed spontaneously-expelled ascarids in raccoons' feces and treated these animals with an ascaricide. Recovery of ascarids from grouped raccoons (Nos. 1-5) after the first ascaricide treatment also indicated a lasting $B$. procyonis infection in this park. Raccoons Nos. 9 and 10 were caged together and both were parasitized by B. procyonis; one harbored developing adults and the other harbored fully-matured adults, respectively. This finding strongly suggests that one was infected initially and the other acquired the infection via infective eggs contaminating the shared cage. In view of the housing arrangements and feeding of raccoons in this facility, we could exclude the possibility of infection via encapsulated larvae in paratenic (intermediate) hosts.

Since successful infection from embryonated eggs is known to occur in young raccoons [11], it seems more likely that raccoon No. 10 (aged at least 5 years) harbored the original infection and contaminated the shared cage, and that raccoon No. 9 (aged $<1.5$ years) subsequently acquired the infection. Embryonation of shed eggs takes from 11-14 days to 3-4 weeks to become infective to young raccoons and intermediate hosts. Raccoon No. 10 was donated by a pet owner 8 weeks prior to the start of the outbreak in midJuly, implying that the earliest time of infection of raccoon No. 9 was middle or late June. The prepatent period of $B$. procyonis infection in raccoons was reported to be approximately 63 (50-76) and 35 (32-38) days after ingestion of embryonated eggs or encapsulated larvae in the intermediate host, respectively [11]. Accordingly, it is highly possible that raccoon No. 9 that expelled developing adults after the first ascaricide treatment did not shed ascarid eggs in the feces even at the time the first clinical signs in rabbits were noted. Consequently, the $B$. procyonis infection of raccoon No. 9 is not responsible for the outbreak of disease in the rabbits. This raccoon may have commenced shedding eggs in the feces around the time of the first fecal examination. The validity of this speculation was partially supported by the demonstrated susceptibility of raccoon No. 9, but not No. 10, to infection via eggs (Table 3).

Clinical signs of cerebrospinal larva migrans due to $B$. procyonis appear as early as 7-9 days after oral inoculation of mice with embryonated eggs $[8,17,22]$. Nine days before neurological signs were observed in rabbits, the park experienced an episode of water overflow due to a typhoon, during which caretakers transferred all rabbits to the second rabbit enclosure (nearest to a cage housing infected raccoons on the middle level of the park). We suspect that dispersion of old raccoon feces or contaminated soil/debris under the caged raccoons at that time may have facilitated ingestion of embryonated $B$. procyonis eggs by the rabbits.

The regular administration of the ascaricide to the raccoons was interrupted, and 11 fecal samples collected on day 40 after the second treatment contained one sample positive for B. procyonis eggs; 1,386 EPG from raccoon No. 9. Autopsy of all kept raccoons revealed 4 infected animals (Nos. 6-9) as shown in Table 3. Raccoon No. 9 harbored fully-mature as well as juvenile ascarids in the intestinal lumen, whereas almost all luminal B. procyonis from raccoons Nos. 7 and 8 were in the developing form (Fig. 3).

The recurrence of $B$. procyonis infection in kept raccoons may feasibly be ascribed to: 1) delay of the third course of treatment with the ascaricide, 2) incomplete decontamination of the raccoons' cages, and 3) transfer of juvenile raccoons (Nos. 7 and 8) to a cage that previously housed infected raccoons. Although the raccoons' residence or metal cages and soil possibly contaminated with ascarid eggs were thoroughly flamed by a portable propane torch, feces-contaminated wooden pedestals under metal mesh cages remained unflamed. Juvenile raccoons are known to be highly susceptible to ascarid infection [23, 24]. Further, interruption of regular ascaricide treatment permitted luminal growth of $B$. procyonis that survived the first and/or second ascaricide treatment in the intestinal wall. The route of infection of raccoon No. 6 of a 9-year-old was not identified: one male ascarid could possibly have escaped and survived repeated ascaricide treatments, but no feasible explanation was given for the other juvenile form, as this mother raccoon was distant from her offspring. 
Table 3. Recovery of B. procyonis from the intestine of raccoons at autopsy

\begin{tabular}{|c|c|c|c|c|c|}
\hline \multirow{2}{*}{$\begin{array}{c}\text { Raccoon } \\
\text { No. }\end{array}$} & \multicolumn{3}{|c|}{ Parasites in the lumen } & \multirow{2}{*}{$\begin{array}{l}\text { Parasites } \\
\text { in the wall }\end{array}$} & \multirow{2}{*}{$\begin{array}{l}\text { Total number } \\
\text { of parasites }\end{array}$} \\
\hline & Female & Male & Juvenile & & \\
\hline $1-5$ & 0 & 0 & 0 & 0 & 0 \\
\hline 6 & 0 & 1 & 1 & $\mathrm{NE}^{\mathrm{b})}$ & 2 \\
\hline 7 & 13 & 12 & 29 & 3 & 57 \\
\hline 8 & 25 & 23 & 99 & 2 & 149 \\
\hline 9 & 4 & 2 & 2 & 8 & 16 \\
\hline $10^{\mathrm{c})}$ & 0 & 0 & 0 & $\mathrm{NE}$ & 0 \\
\hline 11,12 & 0 & 0 & 0 & 0 & 0 \\
\hline
\end{tabular}

a) Ascarids less than $10 \mathrm{~mm}$ long were detected by tissue digestion.

b) Not examined.

c) Died accidentally at 22 days before autopsy of all remaining raccoons.

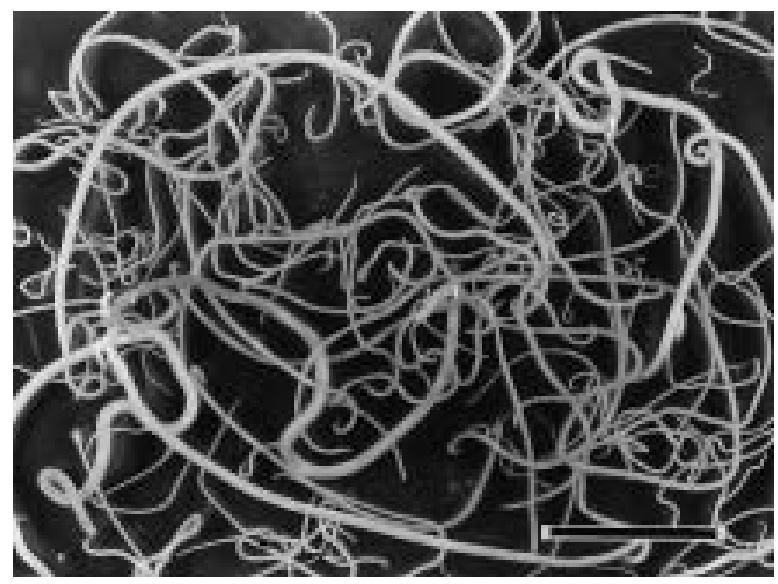

Fig. 3. Developing B. procyonis adults collected from the intestine of a young raccoon (No. 8) at autopsy. Not fixed. Bar=30 $\mathrm{mm}$.

Since B. procyonis eggs are known to maintain their infectivity for more than 9 years under suitable conditions [16], most of contaminated areas in the park were covered by concrete paving, and all raccoon cages and housing were burned and buried to prevent future outbreaks. In spite of these efforts by this park, sporadic infection with $B$. procyonis larvae was still found in rabbits in the spring and summer of 2001 (Furuoka and Sato, unpublished data), indicating the difficulty of a clearance of contaminated areas.

Raccoons are well-adapted to both rural and urban environments in Japan, and the population size of naturalized raccoons increases more and more in several prefectures such as Hokkaido, Kanagawa, Aichi and Gifu [7, 17]. Although B. procyonis has not been found from wild raccoons in Japan, infected raccoons are widely dispersed as personal pets in close contact with owner's family. Primarily, pet owners should be aware of the potential risk of serious zoonosis caused by B. procyonis for their families, and should consider the potential risk of the disease for their neighbors by donation or release of their raccoons. Public health workers as well as public health authorities in Japan should be aware that urgent control measures against pet- or naturalized raccoons and their possible $B$. procyonis infec- tion are critically important to protect the country from this imported zoonosis.

ACKNOWLEDGEMENTS. We express our sincere thanks to staffs of the wildlife park, particularly two caretakers, for their intensive cooperation, and to Dr. Kevin R. Kazacos, School of Veterinary Medicine, Purdue University, and Dr. Nobuaki Akao, School of Medicine, Tokyo Medical and Dental University, for their invaluable suggestions and review of the manuscript. This work was supported in part by a Grant-in-Aid (No. 13460137) from the Japan Society of Promotion of Science.

\section{REFERENCES}

1. Asakawa, M., Kurachi, T. and Wildl. Ecol. Soc. 1999. Parasitic helminths of raccoons in Hokkaido, Japan. Jpn. J. Zoo. Wildl. Med. 4: 101-103.

2. Conraths, F. J., Bauer, C., Cseke, J. and Laube, H. 1996. Arbeitsplatzbedingte Infektionen des Menschen mit dem Waschbärspulwurm Baylisascaris procyonis. Arbeitsmed. Sozialmed. Umweltmed. 31: 13-17 (in German with English summary).

3. Cunningham, C. K., Kazacos, K. R., McMillan, J. A., Lucas, J. A., McAuley, J. B., Wozniak, E. J. and Weiner, J. B. 1994. Diagnosis and management of Baylisascaris procyonis infection in an infant with nonfatal meningoencephalitis. Clin. Infect. Dis. 18: 868-872.

4. Fox, A. S., Kazacos, K. R., Gould, N. S., Heydemann, P. T., Thomas, C. and Boyer, K. M. 1985. Fatal eosinophilic meningoencephalitis and visceral larva migrans caused by the raccoon ascarid Baylisascaris procyonis. New Engl. J. Med. 312: 1619-1623.

5. Goldberg, M. A., Kazacos, K. R., Boyce, W. M., Ai, E. and Katz, B. 1993. Diffuse unilateral subacute neuroretinitis: morphometric, serologic, and epidemiological support for Baylisascaris as a causative agent. Ophthalmology 100: 16951701.

6. Huff, D. S., Neafie, R. C., Binder, M. J., De León, G. A., Brown, L. W. and Kazacos, K. R. 1984. The first fatal Baylisascaris infection in humans: an infant with eosinophilic meningoencephalitis. Pediatr. Pathol. 2: 345-352.

7. Ikeda, T. 2000. [Problems caused by naturalized raccoons in Japan]. [Iden] 54: 59-63 (in Japanese).

8. Kazacos, K. R. 1986. Raccoon ascarids as a cause of larva migrans. Parasitol. Today 2: 253-255. 
9. Kazacos, K. R. 1997. Visceral, ocular, and neural larva migrans. pp. 1459-1473. In: Pathology of Infectious Diseases, Vol. II (Connor, D. H., Chandler, F. W., Schwartz, D. A., Manz, H. J. and Lack, E. E. eds.), Appleton, Stamford.

10. Kazacos, K. R. 2001. Baylisascaris procyonis and related species. pp. 301-341. In: Parasitic Diseases of Wild Mammals, 2nd ed. (Samuel, W. M., Pybus, M. J. and Kocan, A. A. eds.), Iowa State Univ. Press, Ames.

11. Kazacos, K. R. and Boyce, W. M. 1989. Zoonosis update: Baylisascaris larva migrans. J. Am. Vet. Med. Assoc. 195: 894903.

12. Kazacos, K. R., Gavin, P. J., Shulman, S. T., Tan, T. Q., Gerber, S. I., Kennedy, W. A., Murray, W. J. and Mascola, L. 2002. Raccoon roundworm encephalitis: Chicago, Illinois, and Los Angeles, California, 2000. $M M W R^{T M}$ 50: 1153-1155.

13. Kazacos, K. R., Raymond, L. A., Kazacos, E. A. and Vestre, W. A. 1985. The raccoon ascarid: a probable cause of human ocular larva migrans. Ophthalmology 92: 1735-1744.

14. Kazacos, K. R., Reed, W. M., Kazacos, E. A. and Thacker, H. L. 1983. Fatal cerebrospinal disease caused by Baylisascaris procyonis in domestic rabbits. J. Am. Vet. Med. Assoc. 183: 967-971.

15. Küchle, M., Knorr, H. L. J., Medenblik-Frysch, S., Weber, A., Bauer, C. and Naumann, G. O. H. 1993. Diffuse unilateral subacute neuroretinitis syndrome in a German most likely caused by the raccoon roundworm, Baylisascaris procyonis. Graefe's Arch. Clin. Exp. Ophthalmol. 231: 48-51.

16. Lindquist, W. D. 1978. Baylisascaris procyonis for testing anthelminthics against migratory ascarids. Am. J. Vet. Res. 39: 1868-1869.

17. Miyashita, M. 1993. Prevalence of Baylisascaris procyonis in raccoons in Japan and experimental infections of the worm in laboratory animals. [Seikatsu Eisei] 37: 137-151 (in Japanese with English summary).

18. Moertel, C. L., Kazacos, K. R., Butterfield, J. H., Kita, H., Watterson, J. and Gleich, G. J. 2001. Eosinophil-associated inflammation and elaboration of eosinophil-derived proteins in 2 children with raccoon roundworm (Baylisascaris procyonis) encephalitis. Pediatrics 108: e93.

19. Park, S. Y., Glaser, C., Murray, W. J., Kazacos, K. R., Rowley, H. A., Gredrick, D. R. and Bass, N. 2000. Raccoon roundworm (Baylisascaris procyonis) encephalitis: case report and field investigation. Pediatrics 106: e56.

20. Rowley, H. A., Uht, R. M., Kazacos, K. R., Sakanari, J., Wheaton, W. V., Barkovich, A. J. and Bollen, A. W. 2000. Radiologic-pathologic findings in raccoon roundworm (Baylisascaris procyonis) encephalitis. Am. J. Neuroradiol. 21: 415420.

21. Sato, H., Furuoka, H. and Kamiya, H. 2002. First outbreak of Baylisascaris procyonis larva migrans in rabbits in Japan. Parasitol. Int. 51: 105-108.

22. Sheppard, C. H. and Kazacos, K. R. 1997. Susceptibility of Peromyscus leucopus and Mus musculus to infection with Baylisascaris procyonis. J. Parasitol. 83: 1104-1111.

23. Snyder, D. E. and Fitzgerald, P. R. 1985. The relationship of Baylisascaris procyonis to Illinois raccoons (Procyon lotor). J. Parasitol. 71: 596-598.

24. Snyder, D. E. and Fitzgerald, P. R. 1987. Contaminative potential, egg prevalence, and intensity of Baylisascaris procyonisinfected raccoons (Procyon lotor) from Illinois, with a comparison to worm intensity. Proc. Helminthol. Soc. Wash. 54: 141145.

25. Yamada, D., Oku, Y., Nonaka, N., Asakawa, M., Ikeda, T., Asano, M., Akamatsu, R., Matoba, Y. and Kamiya, M. 2000. Studies on the parasite fauna of raccoon (Procyon lotor) naturalized in Hokkaido, Japan. Parasitol. Int. 49 (Suppl): 91. 